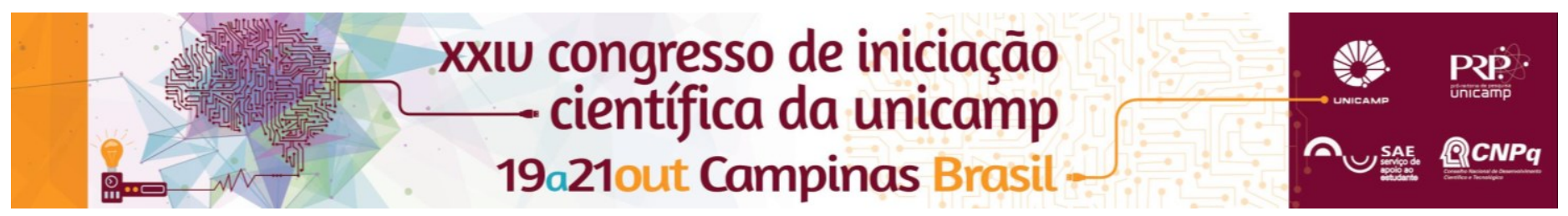

\title{
Evaluation of the growth rate of immature of Chrysomya albiceps (Diptera: Calliphoridae) raised in laboratory under different food substrates
}

\section{Thamiris G. Smania*, Fábio Rezende, Arício X. Linhares, Patrícia J. Thyssen}

\begin{abstract}
Insects associated with decaying bodies are used in forensics to obtain relevant information to advance an investigative process. The estimated post mortem interval (PMI), for example, can be calculated based on information on the dipteran life cycle. In this study, we evaluated the growth rate of immature of Chrysomya albiceps reared in laboratory under controlled temperature and different food substrates, from the measurement of larval lengt aimed at creating a mechanism to calculate the PMI.
\end{abstract}

\section{Key words:}

Forensic entomology, larval development, blowfly.

\section{Introduction}

Forensic Entomology is the science that studies insects and other arthropods to associate this knowledge to criminal procedures (Catts \& Haskell, 1990; Thyssen, 2011). Insects most commonly used in these studies are flies, especially Calliphoridae family, as they are among the first to find a corpse, laying eggs in the early hours after death (Reed, 1958). Several factors may influence the rate of development of these insects such as temperature, humidity, photoperiod, larval density, interand intra-specific competition, and even food substrate, and thereby can accelerate or delay the development of immature or change the viability of adults.

In this study, we evaluated the growth rate of immature Chrysomya albiceps created in laboratory under six different types of substrate (domestic pig - Sus scrofa L. heart, liver, intestine, tongue, muscle and lung) under controlled temperature of $30^{\circ} \mathrm{C}$ from the measurement of larval length, in order to have information that can be used to estimate the postmortem interval (PMI).

\section{Results and Discussion}

Experimental groups consisted on 100 larvae deposited in plastic vials containing different types of substrate in an approximate proportion of $1.0 \mathrm{~g} / \mathrm{larva}$ for complementing the development to pupae at a temperature of $30^{\circ} \mathrm{C}$. Every 12 hours, 10 larvae were taken randomly, fixed in alcohol formaldehyde and acetic acid solution (AFA), for subsequent measurement of its body length.

The total time of development of immatures reared in different food sources ranged from $96 \mathrm{~h}$ to $132 \mathrm{~h}$ (Figure 1) and the average length $(\mathrm{mm})$ for each experimental group, as indicated by one-way ANOVA were significantly different $(F=5.97 ; P<0.0001)$.

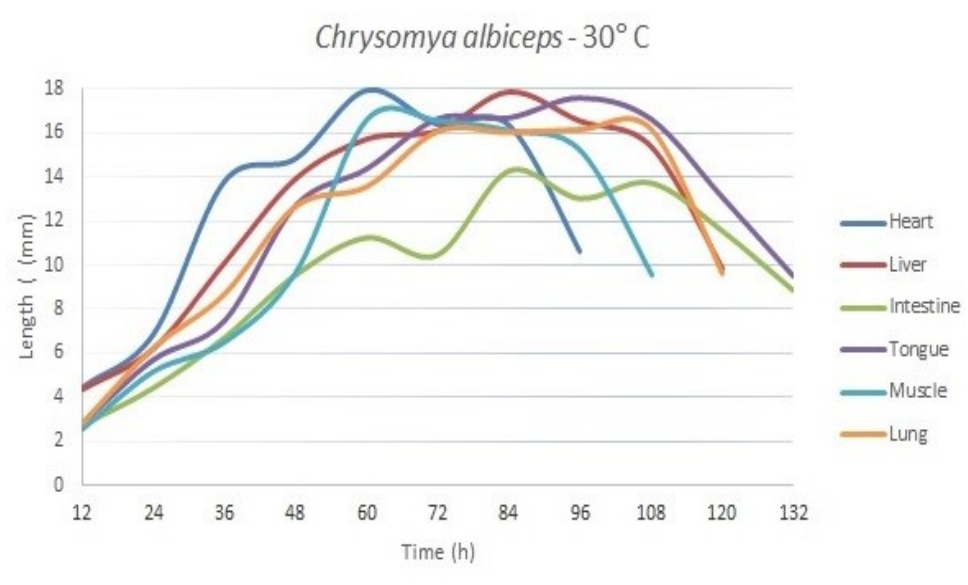

Figure 1. Mean length ( $\mathrm{mm}$ ) of immature groups created under different food substrates.

\section{Conclusions}

The total time of larval development may vary according to the food supply under which the immature is exposed, and therefore its body length. Since the length parameter can be used as an important tool for estimating the IPM, such data should be observed carefully in order to avoid under- or over-estimation of the time of death during investigative work.

\section{Acknowledgement}

Fapessp Fundação de Amparo à Pesquisa do Estado de São Paulo

[1]CATTS, E.P. \& HASKELL, N.H. 1990. Entomology and death: a procedural guide. Clemson, Joyce's Print Shop, 180 p. [2] REED, H. B. 1958. A study of dog carcass communities in Tennessee, with special reference to the insects. The American Midland Naturalist, 59(1): 213 45.

[3]THYSSEN, P.J. 2011. Entomologia Forense. In: Marcondes CB (org.) Entomologia Médica e Veterinária. 2 ed. Rio de Janeiro: Atheneu. pp. 129137. 